\title{
External tracheal stenting for pediatric airway obstruction: A word of caution
}

\author{
Roosevelt Bryant III, MD
}

\footnotetext{
From the Division of Cardiovascular Surgery, The Heart Institute, Cincinnati Children's Hospital Medical Center, Cincinnati, Ohio.

Disclosures: Author has nothing to disclose with regard to commercial support.

Received for publication Dec 30, 2016; accepted for publication Jan 10, 2017; available ahead of print Feb 22, 2017.

Address for reprints: Roosevelt Bryant III, MD, Pediatric Heart Transplant Program, Cincinnati Children's Hospital Medical Center, The University of Cincinnati College of Medicine, 3333 Burnet Ave, MLC 2004, Cincinnati, OH 45229 (E-mail: Roosevelt.BryantIII@cchmc.org).

J Thorac Cardiovasc Surg 2017;153:1178-9

$0022-5223 / \$ 36.00$

Copyright (c) 2017 by The American Association for Thoracic Surgery

http://dx.doi.org/10.1016/j.jtcvs.2017.01.028
}

In this issue of the Journal, Ando and coauthors ${ }^{1}$ have presented their experience with a modification of the polytetrafluoroethylene external airway stent for pediatric patients with tracheobronchomalacia (TBM). Their work adds to an increasing number of surgical procedures reported to address this disease. As the surgical therapy of TBM expands, a framework for the application of these therapies is needed to assess their clinical efficacy and to select the appropriate therapy for each patient. Baxter and Dunbar $^{2}$ defined the clinical condition of tracheomalacia in 1963. They described it as a weakness of the tracheal wall from softening of the supporting cartilage or hypotonia of the supporting myoelastic fibers. The description was perhaps prophetic in terms of our current understanding of tracheomalacia. That is, there are both static and dynamic components to tracheomalacia. ${ }^{3}$ Postmortem studies in patients with tracheomalacia have shown cartilage deformation to be a characteristic feature of tracheomalacia and protrusion of the posterior tracheal membrane into the airway lumen. That posterior protrusion has been termed excessive dynamic airway collapse.

The technique described by Ando and coauthors ${ }^{1}$ addresses both the static and dynamic pathologic components of TBM. The polytetrafluoroethylene external stent is applied to the cartilaginous and membranous components of the airway, but as 2 separate stents rather than sutured together. This modification seeks to optimize the growth potential of the airway. Although they found this approach to be effective in improving the airway diameter and reducing its collapsibility, it was associated with significant morbidity and mortality. The actuarial freedom from death or reoperation was $74.8 \%$ at 3 years, and the operative mortality reached $30 \%$ in patients who had a combination of tracheal and left bronchial stents.

Considering polytetrafluoroethylene external stenting in the context of other reported surgical therapies for TBM, 2 broad categories of surgical procedures are evident: direct and indirect tracheobronchial repairs. The indirect repairs

\section{References} 1013-23.

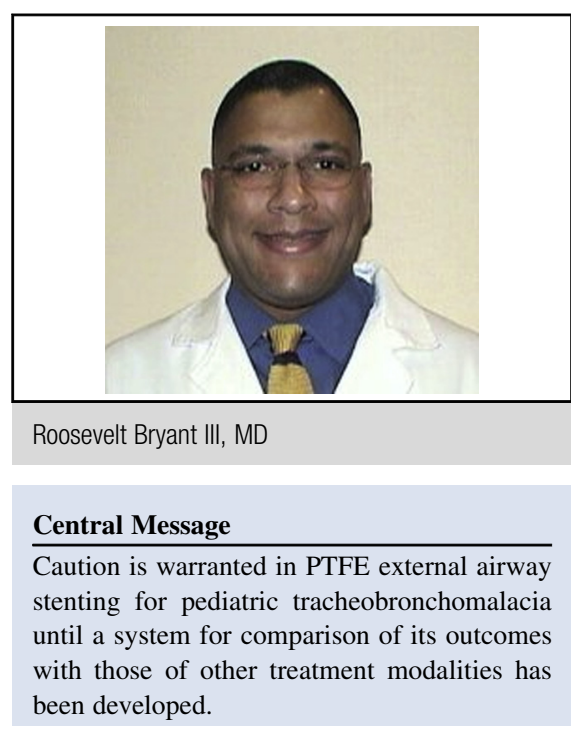

See Article page 1167.

do not address the intrinsic pathology of the airway. Instead, they alter anatomic relationships that exacerbate symptoms through extrinsic compression. Aortopexy has been the mainstay of indirect repair. Its primary drawback, however, is that it does not address the dynamic component of the airway pathology. The mortality is as high as $6 \%$ in some series. ${ }^{5}$ Direct repairs, such as posterior tracheopexy, address the dynamic component of the airway pathology without dealing with the static component. Still other repairs, such as internal stenting with metal or silicone, are fraught with significant morbidity and significant mortality. ${ }^{6}$ Bairdain and colleagues ${ }^{3}$ from Boston Children's Hospital have proposed a grading scale to define the severity of TBM. Their scale may allow uniformity when assessing the extent and severity of disease and may provide a framework for the application of these techniques to each patient's pathology. It may also provide a basis for comparison of outcomes with each of these techniques. Ando and coworkers ${ }^{1}$ have made an important contribution to the surgical treatment of TBM, but caution is warranted in the application of this technique until a system for comparison of its outcomes to other treatment modalities has been developed.

1. Ando M, Nagase Y, Hasegawa H, Takahash Y. External stenting: a reliable technique to relieve airway obstruction in small children. J Thorac Cardiovasc Surg. 2017; 153:1167-77.

2. Baxter JD, Dunbar JS. Tracheomalacia. Ann Otol Rhinol Laryngol. 1963;72: 
3. Bairdain S, Zurakowski D, Baird CW, Jennings RW. Surgical treatment of tracheobronchomalacia: a novel approach. Paediatr Respir Rev. 2016;19:16-20.

4. Murgu SD, Colt HG. Tracheobronchomalacia and excessive dynamic airway collapse. Respirology. 2006;11:388-406.
5. Torre M, Carlucci M, Speggiorin S, Elliott MJ. Aortopexy for the treatment of tracheomalacia in children: review of the literature. Ital J Pediatr. 2012;38:62.

6. Fraga JC, Jennings RW, Kim PC. Pediatric tracheomalacia. Semin Pediatr Surg. 2016:25:156-64. 